\title{
REFLEX̃̃es SOBRE O PROJETO ÉTICO-POLítico PROFISSIONAL DO SERVIÇO SOCIAL E A DEMOCRATIZAÇÃo
}

\author{
REFLECTIONS ABOUT THE PROFESSIONAL ETHICAL-POLITICAL PROJECT OF \\ SOCIAL WORK AND DEMOCRATIZATION
}

Aurea Satomi Fuziwara ${ }^{1}$

\section{RESUMO}

O presente artigo apresenta reflexões sobre o projeto ético-político profissional e a defesa das conquistas democráticas brasileiras, tendo como fio condutor a análise sobre democracia e democratização, e o desafio de reafirmar a democracia como princípio do Código de Ética Profissional na defesa de um projeto profissional vinculado à construção de uma nova ordem societária.

PALAVRAS-CHAVE: Projeto ético-político. Serviço Social. Democracia.

\section{ABSTRACT}

This paper comes up with reflections about the ethic-political professional project and the defense of brasilian's democratics achievements, adopting the analysis about democracy and democratization, and the challenge due to reaffirm democracy as a principle of the Professional Ethics Code in the defense of a professional project linked to the development of a new social order.

KEYWORD: Ethical-political project. Social Work. Democracy.

\footnotetext{
${ }^{1}$ Assistente social, mestre e doutora em Serviço Social pela Pontifícia Universidade Católica de São Paulo (PUC-SP), participante do Núcleo de Pesquisas em Ética e Direitos Humanos (NEPEDH), do Curso de Pós-graduação em Serviço Social da Faculdade de Ciências Sociais da PUC-SP. E-mail: fuziwara.aurea@gmail.com.

Serv. Soc. \& Saúde, Campinas, SP v.15, n. 1 (21), p. 83-100, jan./jun. 2016 ISSN 1676-6806
} 
A "todos os trabalhadores que morreram e lutaram [lutam] pelas liberdades democráticas"

\section{INTRODUÇÃO}

Este artigo foi escrito no contexto de turbulência do início de $2016^{2}$. No percurso das mobilizações desde 2013, pautas que têm como raiz as velhas demandas da classe trabalhadora tomaram vulto frente às disputas político-partidárias. Em meio às denúncias e graves violações de direitos humanos, os conservadores e a direita brasileira expressam posicionamentos nacionalistas e fascistas, apelando à volta da Ditadura e dos Militares, colocando-se exigências históricas ao movimento social.

O debate sobre a democracia tomou o espaço público e privado nos últimos meses, ganhando relevo desde a insatisfação do resultado da disputa acirrada das eleições presidenciais de 2014, quando Dilma Rousseff saiu vitoriosa como a primeira mulher eleita para Presidente do Brasil. Elegeu-se mesmo com as acusações da direita de que era/é apoiadora do aborto (por assumir parte da agenda feminista, ou apenas por ser mulher) e do terrorismo (com ataques cotidianos sobre sua participação na resistência à Ditadura Civil-Militar de 1964), bem como diante da pouca abertura a reivindicações feitas pelo intenso embate com a esquerda que defende mudanças estruturais para o país.

Não pretendemos neste artigo adentrar na análise política pormenorizada sobre as acusações e defesas. Nosso foco nesta reflexão é o chamado Projeto Ético-Político profissional do Serviço Social, conduzido pelas problematizações a respeito do momento de disputa sobre a democracia brasileira, frágil e jovem, e o momento de forte reação conservadora e reacionária ${ }^{3}$.

\footnotetext{
${ }^{2}$ Artigo elaborado em março de 2016.

${ }^{3}$ Parte das reflexões que temos acumulado neste assunto deve-se à participação da autora, nem sempre tão assídua, no Núcleo de Estudos e Pesquisas sobre Ética e Direitos Humanos - NEPEDH/PUCSP, coordenado pela Prof. ${ }^{a}$ Dr. ${ }^{a}$ Maria Lúcia Barroco.

Serv. Soc. \& Saúde, Campinas, SP v. 15, n. 1 (21), p. 83-100, jan./jun. 2016 ISSN 1676-6806
} 
Há grande envolvimento de intelectuais, escritores, artistas, acadêmicos, movimentos sociais, mídia alternativa e observadores internacionais nesta conjuntura. Expressam-se mobilizações de diversas forças na tentativa de um golpe institucional contra o governo federal eleito, situação que se agrava com ações de grupos de "esquerda" que com suas insatisfações também defendem o impeachment da atual Presidente da República do Brasil. São questões contraditórias e de grande complexidade que na velocidade dos acontecimentos podem prejudicar nossa análise e, logo, nossos posicionamentos efetivos.

Deste modo, optamos em abarcar nesta reflexão o Projeto Ético-Político do Serviço Social, tendo como fio condutor a análise sobre democracia e democratização ${ }^{4}$, e a relevância de reafirmarmos a democracia como princípio do Código de Ética Profissional na defesa de um projeto profissional vinculado à construção de uma nova ordem societária.

É crucial buscarmos uma profunda análise da sociedade brasileira, que nesta conjuntura coloca-se como solo confortável para as posições conservadoras e reacionárias. Ellen Wood nos adverte, na obra "A democracia contra o capitalismo" sobre o discurso pós-moderno do "novo pluralismo", que nos faz pensar sobre a advertência marxista a respeito do ecletismo que conciliaria (artificialmente) o inconciliável.

[...] O novo pluralismo afirma ter sensibilidade única às complexidades do poder e das diversas opressões; mas, tal como a variedade antiga, ele tem o efeito de tornar invisíveis as relações de poder que constituem o capitalismo, a estrutura dominante de coerção que interfere em todos os planos de nossa vida pública e privada (WOOD, 2006, p. 223).

\section{FLASHES HISTÓRICOS DO SERVIÇO SOCIAL}

O Serviço Social enfrentou ao longo de sua trajetória questões cruciais da sociedade brasileira, como o conservadorismo. Nos últimos anos da Ditadura CivilMilitar no Brasil (1964-1985), os assistentes sociais se posicionaram com maior vigor, tendo como marco o III Congresso Brasileiro de Assistentes Sociais, conhecido como

\footnotetext{
${ }^{4}$ Este debate foi desenvolvido em nossa tese de doutorado.

Serv. Soc. \& Saúde, Campinas, SP v.15, n. 1 (21), p. 83-100, jan./jun. 2016 ISSN 1676-6806
} 
"Congresso da Virada", em 19795. Um dos atos emblemáticos neste contexto foi a contestação da mesa oficial que seria composta por autoridades ditatoriais, na qual os congressistas deram assento aos representantes do povo, caçando-se a Comissão de Honra e eleição de uma nova, composta pelos representantes da classe trabalhadora. Em frente à mesa havia uma faixa com a dedicatória "por todos os trabalhadores que morreram e lutaram pelas liberdades democráticas". Estes foram atos que refletiram parte da construção ao longo dos meses, por forças de resistência de vários lugares do país. Apesar da Ditadura, as profissionais conseguiam ter contatos entre militantes e pensar as estratégias coletivas.

Essa forma de articulação, em plena Ditadura, driblando, com risco de morte, o cerceamento de liberdades fundamentais como o de ir e vir, de expressão e de participação política, não poderia ocorrer se não tivesse minimamente unidade de posição e de ação. Os documentos históricos versam que os assistentes sociais estavam unidos contra a Ditadura.

Porém, como em toda generalização, é importante verificarmos seus elementos com cuidado. Conforme Netto (2009) os assistentes sociais sempre estiveram na cena política durante a Ditadura de 64. Porém, adverte:

Ao longo de todo o ciclo ditatorial incontável contingente de assistentes sociais apoiou-o abertamente (seja por convicções, seja por oportunismo); inúmeros assistentes sociais assumiram - por indicação política - cargos e postos de responsabilidade em órgãos estatais e públicos; vários assistentes sociais assessoraram serventuários da ditadura e alguns foram mesmo distinguidos pelo regime e seus corifeus. É fato que o grosso da categoria atravessou aqueles anos terríveis sem tugir nem mugir. Nada é mais falso do que imaginar que o [todo] nosso corpo profissional (nele incluídos, naturalmente, docentes e discentes) foi um coletivo de perseguidos ou um corajoso destacamento da resistência democrática.

Mas é igualmente falso supor que todo esse corpo profissional foi um obediente batalhão a bater continência aos donos do poder (p. 29).

Pondera Netto que os profissionais e estudantes estiveram presentes nas lutas de resistência, mas assim como as outras categorias profissionais, o Serviço Social construiu uma "tardia manifestação opositiva à ditadura por parte das instâncias e fóruns representativos da categoria profissional” (NETTO, 2009, p. 30). Neste sentido,

\footnotetext{
${ }^{5}$ Sugerimos a leitura do livro 30 anos do Congresso da Virada, citada nas referências bibliográficas. A versão digital está disponível nos sites do CFESS e CRESS.
}

Serv. Soc. \& Saúde, Campinas, SP v. 15, n. 1 (21), p. 83-100, jan.jun. 2016 ISSN 1676-6806 
É preciso que fique bem claro: o monopólio político e conservador no Serviço Social nas instâncias e fóruns profissionais só pôde ser quebrado, ainda que tardiamente, quando da emersão do proletariado na arena política. Contudo, ele só pôde ser quebrado porque no interior da categoria profissional existiam reais potencialidades para tanto (NETTO, 2009, p. 30-31).

Essa realidade se expressou nas entidades representativas da categoria e no processo de formação, repercutindo também o processo de laicização e de proletarização. O mercado de trabalho e o assalariamento se expandiram. Netto avalia que os profissionais adotaram duas frentes de ação: "na criação de alternativas organizacionais ao conservadorismo e na articulação com colegas que, em outras regiões, movimentavam-se no mesmo sentido" e que o Congresso da Virada "trouxe para a cena política os componentes democráticos até então reprimidos na categoria profissional” (2009, p. 33).

Destaque-se que dois elementos ganham relevo neste Congresso: os assistentes sociais romperam com a ideia central deste ser um evento celebrativo, inclusive naquela edição sendo acusado de haver reverência ao Estado ditatorial "administrada pelo conservadorismo conivente" da categoria, expressando sua exigência concreta de democracia, e posicionou-se junto às demandas da classe trabalhadora (NETTO, 2009, p. 33).

Essa dinâmica não é linear nem consensual, mas apresentou sua tendência hegemônica forçando mudanças no âmbito político e acadêmico da profisssão. A categoria, como o conjunto dos trabalhadores, também foi impulsionada em sua cultura organizativa participando da criação da Central Única dos Trabalhadores (CUT), e do Partido dos Trabalhadores (PT).

A Associação Brasileira de Ensino em Serviço Social (ABESS, hoje Associação Brasileira de Ensino e Pesquisa em Serviço Social - ABEPSS) ganhou fôlego na construção do projeto profissional, com intensificação no campo da pesquisa, posto o engajamento dos assistentes sociais envolvidos nesta área em disputa frente aos impactos da Ditadura no âmbito da educação. A literatura profissional registrou e analisa esta realidade na qual houve importante mobilização nacional na construção das novas Diretrizes Curriculares do curso de Serviço Social. 
Os Conselhos Profissionais também passam por uma grande mudança, pois se antes tinham seus membros nomeados pelo governo, sendo vinculados ao Ministério do Trabalho, tornaram-se autarquias federais e passaram a ter diretorias eleitas pelos próprios assistentes sociais. A mudança de nome expressa à nova perspectiva: ao invés de Conselho de Assistentes Sociais, passam a ser chamados Conselho Regional de Serviço Social e Conselho Federal de Serviço Social, assumindo seu papel de orientador do trabalho profissional e Tribunal de Ética da área, visando orientar, normatizar e fiscalizar a atuação e a ética profissionais. Perspectiva que rompe a lógica corporativista, governamental e assume seu papel de defesa do direito da população quanto ao bom exercício profissional.

Ao longo dos anos 80 e 90, a literatura da área avançou enormemente, mas também expressando ecletismo, nos termos da avaliação de Netto (1996; 2001). Tanto o ecletismo quanto o sincretismo (NETTO, 2001) terão em comum os traços conservadores que vão se reconfigurando em cada conjuntura.

A alternativa de um Serviço Social profissional liberado da tradição positivista e do pensamento conservador não lhe retirará o seu estatuto fundamental: o de uma atividade que responde, no quadro da divisão social (e técnica) do trabalho da sociedade burguesa consolidada e madura, a demandas sociais prático-empíricas (NETTO, 2001, p. 149).

Nestas últimas décadas em que o Projeto Ético-Político profissional adota este posicionamento denominado por Netto como intenção de ruptura tem também como fundamento a definição de que o Serviço Social é uma profissão inserida na divisão social e técnica do trabalho, que emergiu das contradições desta sociedade capitalista. A sua gradativa profissionalização foi uma conquista do coletivo de trabalhadores, propiciando o avanço da fundamentação teórico-metodológica, técnico-operativa e ético-política, no contraditório processo de assalariamento e controle da autonomia profissional.

Problematizamos, deste modo, que apesar desta rica conjuntura de lutas políticas e de construção do projeto profissional pela categoria, exigem-se constantes balanços históricos e analisar afinal quem compõe e o que defende este coletivo profissional.

Nossa memória recente permite afirmar que inúmeras conquistas protagonizadas pelo Conjunto CFESS-CRESS e pela ABEPSS não tiveram a participação ampla e de maioria dos assistentes sociais em cada fase dos seus processos. Novamente é Serv. Soc. \& Saúde, Campinas, SP v. 15, n. 1 (21), p. 83-100, jan./jun. 2016 ISSN 1676-6806 
importante registrar que este fenômeno não se restringe à área do Serviço Social. Porém, as indagações são necessárias principalmente ao tomarmos como vetores nosso Projeto Ético-Político e as entidades da categoria. Questionamos os motivos de em plena democracia termos uma participação reduzida nas grandes mobilizações que vem sendo realizadas nacionalmente.

\section{DEMOCRACIA OU DEMOCRATIZAÇÃO}

[...] as considerações que faço aqui têm como ponto de partida, na trilha de Marx, o fato de que toda formação econômica, de um ponto de vista ontológico, é algo dotado de uma legalidade necessária e, ao mesmo tempo, de um ser-precisamente-assim histórico; portanto, de acordo com seu ser social, formas estruturais - como, em nosso caso, a democracia - só podem ser constituídas do mesmo modo. Por isso, busco aqui tratar a democracia (ou melhor, a democratização, dado que também neste caso segundo uma abordagem ontológica, trata-se sobretudo de um processo e não de uma situação estática) de um ponto de vista histórico, como concreta força política ordenadora daquela particular formação econômica sobre cujo terreno ela nasce, opera, torna-se problemática e desaparece. A distoricização, aqui como alhures, cria sempre fetiches, avaliados positiva ou negativamente, que não esclarecem, mas, ao contrário, obscurecem e confundem os processos sociais concretos (e as leis que os regem). Também a respeito destas questões, fala-se frequentemente da democracia como de uma situação estática, deixando-se de lado, ao caracterizar tal situação, o exame das orientações evolutivas reais, embora somente deste modo seja possível uma correta conceituação do problema. Para sublinhar isso, preferi usar o termo "democratização" em vez de “democracia” (LUKÁCS, 2011, p. 85, destaque nosso).

Sabemos o quanto a atual democracia brasileira é ainda frágil, exigindo inclusive mudanças estruturais. Neste sentido, existem atualmente movimentos sociais que reivindicam a Reforma Política, como o Plebiscito Popular pela Constituinte, ou ainda questionando a dívida pública, como os movimentos Auditoria Cidadã da Dívida e o POEMA - Política Econômica da Maioria ${ }^{6}$. Estas duas frentes de reivindicações se inserem na construção de reformas estruturais, que permitam a construção do processo que entendemos ser de democratização. Entram nestas agendas as questões da mobilidade urbana, direito à cidade, reforma agrária, garantia dos direitos de indígenas e

\footnotetext{
6 A Política Econômica da Maioria (POEMA) é um movimento sem ligação com partidos políticos que luta por justiça social através da popularização de medidas fiscais e tributárias que financiem os direitos que temos garantidos na nossa Constituição Federal, e que são negados em benefício de uma minoria privilegiada.

Serv. Soc. \& Saúde, Campinas, SP v.15, n. 1 (21), p. 83-100, jan./jun. 2016 ISSN 1676-6806
} 
quilombolas, mas cujo discurso também exige alterações efetivas para garantir a participação popular.

Vivenciamos atualmente no Brasil forte polarização política, com a distorcida ideia de confronto entre dois projetos de País. Há uma frente que defende o governo Dilma, carregando diferentes níveis de defesa desta gestão. O outro polo agrega desde reacionários, defensores da volta da Ditadura Militar, até descontentes que vestem preto em repúdio à corrupção (que na atualidade, por meio da grande mídia vem sendo atribuída exclusivamente ao PT, embora existam graves denúncias envolvendo quase todos os partidos). Há um crescente e importante questionamento à "mídia golpista", a qual transmite reportagens parciais e tendenciosas. Neste contexto, cresceu o questionamento à rede Globo de televisão, reivindicando-se a não renovação da concessão pública para a exploração comercial, bem como às revistas e jornais que fazem a defesa das agendas conservadoras e vem também gerando muito medo na população. Além do medo, o agravamento da violência com o mesmo discurso polarizado que já fez cinco bebês vítimas do ódio, onde a pessoa que estava com tal infante acabou sendo agredida, hostilizada verbalmente, tendo que recorrer à ajuda no meio de tal situação. Avolumam-se episódios de pessoas com simples trajes vermelhos sendo atacadas, por se entender que há uma defesa do governo. Observe-se que pessoas vestindo camisetas amarelas (geralmente do time da seleção brasileira de futebol) não foram atacadas de tal maneira, o que ilustra parte dos conflitos causados pelo grupo que tem horror às ações mínimas do Estado como a transferência de renda por meio do Programa Bolsa Família.

O que é paradoxal é que as mudanças na vida dos beneficiários dos programas federais foram em geral restritas à esfera do consumo (sem mobilidade social), mas tal fato gera horror e ódio por parte de uma importante parcela da população brasileira. Em diferentes níveis, há profissionais de Serviço Social que se agregam aos que questionam a corrupção, mas com a visão midiática e parcial que não possibilita aprofundar a análise. Além disso, há profissionais que fazem o discurso conservador que exige a redução da maioridade penal e concordam que deve ser negada a adoção de crianças por pessoas que não se declarem heterossexuais.

Esta nossa reflexão apoia-se nas discussões que ocorrem nos circuitos dos movimentos sociais, nas redes sociais e em atividades acadêmicas, apreendendo 
elementos para depurar o que entendemos ser a recusa da efetiva democratização na sociedade brasileira. Os valores apresentados de forma genérica são em geral discursivos e sem coerência com os posicionamentos efetivos. Nosso questionamento sobre a frágil democracia foi gerada nestas contradições vividas no movimento social e no trabalho profissional, vindo assim a compor o projeto de pesquisa de doutorado em 2009 .

Nestes estudos encontramos nas análises de Ellen Wood, que vivemos a democracia formal:

[...] A questão é antes que a associação do capitalismo com a 'democracia formal' representa uma unidade contraditória de avanço e recuo, tanto um aperfeiçoamento quanto uma desvalorização da democracia. A 'democracia formal' é com certeza um aperfeiçoamento das formas políticas a que faltam liberdades civis, o domínio do direito e o princípio da representação. Mas é ela também, e ao mesmo tempo, uma subtração da substância da ideia democrática, aquela a que se liga histórica e estruturalmente ao capitalismo (2006, p. 216).

A autora demonstra que à medida que se avança na possível substância democrática, há conflitos severos porque o capitalismo tolera e administra um certo nível dessa democracia formal, mas desde que não se questione as estruturas. Portanto, é fundamental salientar que o Serviço Social construiu uma concepção de Democracia, num conjunto de valores e princípios defendidos no seu próprio processo de consolidação como profissão inserida na divisão social e técnica do trabalho. Vale retomar que o Código de Ética dos assistentes sociais traz como princípios fundamentais:

I. Reconhecimento da liberdade como valor ético central e das demandas políticas a ela inerentes - autonomia, emancipação e plena expansão dos indivíduos sociais;

II. Defesa intransigente dos direitos humanos e recusa do arbítrio e do autoritarismo;

III. Ampliação e consolidação da cidadania, considerada tarefa primordial de toda sociedade, com vistas à garantia dos direitos civis sociais e políticos das classes trabalhadoras;

IV. Defesa do aprofundamento da democracia, enquanto socialização da participação política e da riqueza socialmente produzida; 
V. Posicionamento em favor da equidade e justiça social, que assegure universalidade de acesso aos bens e serviços relativos aos programas e políticas sociais, bem como sua gestão democrática;

VI. Empenho na eliminação de todas as formas de preconceito, incentivando o respeito à diversidade, à participação de grupos socialmente discriminados e à discussão das diferenças;

VII. Garantia do pluralismo, através do respeito às correntes profissionais democráticas existentes e suas expressões teóricas, e compromisso com o constante aprimoramento intelectual;

VIII. Opção por um projeto profisssional vinculado ao processo de construção de uma nova ordem societária, sem dominação, exploração de classe, etnia e gênero;

IX. Articulação com os movimentos de outras categorias profissionais que partilhem dos princípios deste Código e com a luta geral dos/as trabalhadores/as;

X. Compromisso com a qualidade dos serviços prestados à população e com o aprimoramento intelectual, na perspectiva da competência profissional;

XI. Exercício do Serviço Social sem ser discriminado/a, nem discriminar, por questões de inserção de classe social, gênero, etnia, religião, nacionalidade, orientação sexual, identidade de gênero, idade e condição física.

É inegável em qualquer debate a pertinência e atualidade destes princípios. Retomando as situações descritas sobre as atitudes irracionalistas de pessoas que passaram a agredir qualquer pessoa que trajasse vestes vermelhas, associando-as ao socialismo ou ao comunismo (nem cabendo aqui discutir a total distorção destas pessoas sobre o que entendem ser estas bandeiras ou formas políticas), bem como à defesa da corrupção que estaria sendo praticada "pelo governo do PT", queremos levantar não simplesmente estas situações grotescas, mas o fio da navalha que pode dividir os assistentes sociais que se colocam defensores do Projeto Ético-político profissional hegemônico.

Trata-se, portanto, de um arriscado movimento analítico que estamos nos colocando neste artigo, para refletir e avançar na defesa da democratização.

Ao pesquisar a inserção da categoria nas lutas democráticas e na construção do projeto ético-político profissional, Netto (1996) situa esta "virada" como a intenção de 
ruptura. Em um recorte de sua rica elaboração, é de suma importância considerar que "a magnitude dessa [intenção] de ruptura foi hiperdimensionada" e seu alerta de que talvez nos atermos aos conteúdos dos documentos elaborados nos espaços democráticos do Conjunto CFESS-CRESS não nos possibilitam adentrar às questões de fundo deste Projeto profissional. Refere Netto que estes documentos trazem um perfil ideopolítico e o retrato militante de combatentes anticapitalistas. "Nada mais distanciado da realidade: o conservadorismo nos meios profissionais tem raízes profundas e se engana quem o supuser residual" (p. 112).

Nesta conjuntura em que os reacionários e conservadores encontram terreno livre para vociferar os mais impactantes posicionamentos, há também uma abertura para que os profissionais do Serviço Social engrossem esse coral. O que se apresenta como desafio para quem defende a democratização é a persistência de trabalhar coletivamente para o enfrentamento destes posicionamentos, elucidando seus fundamentos e debatendo as suas contradições.

Evidentemente, esta realidade tem muitas nuances e matizes. Os discursos polarizados podem levar a ideias e posições fundamentalistas, ou seja, dogmáticas e sem possibilidade de debate democrático. Ao mesmo tempo, este contexto de explicitação de diferenças é um momento histórico rico de possibilidades, desde que nos empenhemos na correta análise (não de verdade absoluta, mas de maior aproximação com a vida real dos sujeitos).

É fato que persiste uma voz coletiva nos documentos do conjunto CFESSCRESS, da ABEPSS e da ENESSO (Executiva Nacional de Estudantes de Serviço Social), nas quais disputamos valores e estratégias. A permanência ao longo destas décadas de posicionamentos, por exemplo, em defesa dos Direitos Humanos da Criança e do Adolescente, contra a redução da idade de imputabilidade penal, contra o uso e inquirição de crianças vitimizadas para obtenção de provas criminais, etc, evidenciam o tipo de bandeiras que a categoria tem empunhado. O debate sobre o direito à convivência familiar e comunitária não é necessariamente uma pauta conservadora, senão, um tema que deveria estar em disputa dentro do projeto democratizante que exija a ruptura da desigualdade em diversas dimensões. Na mesma direção, o acúmulo de debates sobre o direito da mulher ao seu corpo é visível nos documentos que gradativamente avançam em defesa da agenda feminista e classista, 
de posicionamentos contra toda forma de opressão de gênero, agregando-se às questões da identidade e livre orientação sexual, à tomada de posição pelo direito ao aborto. Muitas outras campanhas vão apresentando agendas e processos que tratam tanto das lutas gerais dos trabalhadores quanto de especificidades teóricometodológicas e ético-políticas da categoria profissional.

Porém, o crescimento do número de pessoas formadas em Serviço Social, principalmente na última década, nos traz questões muito sérias. As formações, seja pelo Ensino à Distância $(\mathrm{EaD})$, seja pelo curso presencial precarizado exigem enfrentar mais a fundo os impactos da mercantilização do ensino. É preciso questionar que tipo de dinâmica de formação, que práticas pedagógicas, que intervenções éticopolíticas são vivenciadas pelos futuros profissionais. Se os cursos apresentam deficiências, quais as estratégias coletivas de se afirmar o Projeto Ético-político no percurso da formação acadêmica? Se estamos tratando de questões estruturais, quais as ações efetivas de compor um coletivo de docentes do ensino privado para questionar os rumos desta formação? No âmbito individual, como defender a formação profissional sem recair na culpabilização individual - mas também nos posicionarmos eticamente perante o estudante, que é "cliente da empresa", mas que na condição de usuário de um serviço privado de educação, é antes um sujeito de nossa atuação profissional? Qual a qualidade da sistematização e produção de conhecimento que temos engendrado nos cursos de pós-graduação e no trabalho nos diferentes espaços sócio-ocupacionais?

Estes elementos ilustram a preocupação deste artigo em pautar que o debate da democracia tomou centralidade nos debates da sociedade, demonstrando que o Brasil realmente não fez o efetivo acerto de contas com a Ditadura Civil-militar, nem enfrentou as raízes da formação brasileira conforme nos provocou a fecunda obra de Florestan Fernandes. A construção do atual Código de Ética, saliente-se, elaborou seus princípios fundamentais que se mostram totalmente pertinentes para este momento de disputa de projeto societário porque se forjou inserido nas lutas dos trabalhadores.

Recorrendo novamente a Netto (1996) no artigo citado, onde o mesmo faz uma análise prospectiva da profissão, nos alerta:

É aqui, na conexão profissional de curto com o médio prazo, que se situa a importância do projeto burguês de hegemonia que se vem adensando no país - uma vez que ele condicionará significativamente 
as modalidades de incidência das transformações societárias no marco do nosso Estado nacional (p. 121).

Se por um lado tivemos a importante conquista legal das 30 horas em 2010, outras frentes de luta se colocaram com vigor: a questão da sindicalização e a disputa por um projeto de sindicato de luta, renovado, não foi um espaço que ocupamos enquanto categoria. Arriscando um comentário a partir da empiria: temos hoje um quadro com um importante contingente de trabalhadores jovens (ou jovens de formação) que atuam em dois locais de trabalho, agregando um emprego formal com alguma garantia, com outro, extremamente precarizado. O discurso liberal e dos anseios pequeno burgueses parecem ser as bases desta adesão, gerando a estratificação dentre os assistentes sociais.

\section{CONSIDERAÇÕES FINAIS}

A crítica da democracia burguesa é indispensável não só para defender a democracia popular, mas também para mostrar seu caráter de mediação na direção da revolução e da democracia socialista. A democracia é uma falsa democracia, porque a massificação se transforma em manipulação por parte do poder político efetivamente restrito. É importante então que se difunda uma 'concepção democrática do mundo', pois essa é a condição para que se ofereça uma resposta convicta à questão: 'a democracia deve ser apenas uma forma política e jurídica do Estado ou deve se transformar num modo de vida concreto para o povo?' Para Lukács, a democracia popular pressupõe a realização de uma profunda reforma cultural, que supera a submissão religiosa, o fascismo e o liberalismo, e completa-se como 'uma verdadeira articulação do poder do povo trabalhador' "7" (DEL ROYO, 2013, p. 140).

Buscamos apresentar uma reflexão dentro desta Conjuntura, mas com o fio condutor com o qual buscamos tensionar o necessário debate da categoria sobre as nossas concepções inseridas na luta social. É fato que o projeto de país que hegemonicamente defendemos no Serviço Social não encontrou forças suficientes no interior dos últimos governos. Inúmeros são os estudos profundos sobre a dinâmica vivenciada ao longo dos governos pós Ditadura Civil-militar de 1964. Reivindicações centrais têm sido feitas desde o processo da construção da Constituição Federal de

\footnotetext{
${ }^{7}$ Estas citações são parte da obra Lukacs, de Leandro Konder, publicado em 1980 pela editora L \& PM, Porto Alegre.

Serv. Soc. \& Saúde, Campinas, SP v.15, n. 1 (21), p. 83-100, jan./jun. 2016 ISSN 1676-6806
} 
1988, embora as mudanças estruturais não tenham se consolidado e nem há sinais de que há tal intencionalidade da grande maioria dos representantes eleitos para o Executivo e para o Legislativo. Ao contrário, segundo o Departamento Intersindical de Assessoria Parlamentar (DIAP) houve o aumento, na nova composição do Congresso Nacional, do número de parlamentares ligados a segmentos mais conservadores entre eles, militares, policiais, religiosos e ruralistas ${ }^{8}$. Os dados retrataram que o atual parlamento é o mais conservador desde 64, tendo as bancadas denominadas como BBB: boi (agronegócio e latifúndio), bala (toda abrangência da segurança e forças policiais) e bíblia (fundamentalistas religiosos), sendo todos com expresso discurso e posicionamentos reacionários e/ou conservadores.

Se este cenário mais amplo nos envolve, que caminhos tensionar no interior do Serviço Social e nas particularidades complexas de seus sujeitos neste país continental? A categoria está inserida nos mais diferentes espaços sócio-ocupacionais, desde a atuação cotidiana e direta com a população, à atuação exclusiva como pesquisadores, formuladores das políticas públicas governamentais, etc. Retomamos a necessidade de unidade deste coletivo profissional, articulado em torno dos princípios éticos afirmados em nosso Código; tais princípios são faróis que nos guiam e que entendidos em seu conjunto exigem constante reflexão e posicionamentos coletivos.

Nesta conjuntura de posicionamentos reacionários, segregadores, fascistas, exige-se que o coletivo de assistentes sociais não perca de vista o legado construído, cujo porte somente foi possível pelo engajamento da categoria liderado por uma vanguarda com claro projeto societário, o comunista.

A literatura profissional vem problematizando a relevância de aprofundarmos as questões técnico-operativas. Porém, sem que estas estejam alinhadas ao conjunto das dimensões teórico-metodológicas e ético-políticas, entende-se que recairemos na lógica instrumental, burocrática e de reduzida participação democrática nos rumos do país.

Parecem jargões superficiais. Contudo, numa sociedade onde uma parte da classe trabalhadora adota o discurso de ódio de classe, e reproduz as práticas fascistas, atacando bebês com seus trajes vermelhos, quem se compromete com o poder popular

\footnotetext{
${ }^{8}$ Matéria publicada em http://justificando.com/2014/10/10/para-diap-congresso-eleito-e-o-maisconservador-desde-1964/

Serv. Soc. \& Saúde, Campinas, SP v. 15, n. 1 (21), p. 83-100, jan.jun. 2016 ISSN 1676-6806
} 
tem que retomar alguns passos atrás. Quando precisamos falar do óbvio, nos vemos compelidas a denunciar a naturalização da barbárie.

A defesa da Democracia é um princípio do Serviço Social, ainda que reconheçamos seus limites na sociedade de classes. O que é preocupante é que à medida que retiramos a historicidade destas concepções, elas se tornam conceitos abstratos, tornando-se difícil pensar suas mediações e contradições.

Sabemos que as legislações são instrumentos construídos processualmente e num momento histórico. A Lei de Regulamentação e o Código de Ética são sínteses de um percurso político e teórico que trazem parte dos fundamentos da profissão. Estes representam parte da sistematização de nossos princípios e valores como resultado deste rico processo de debates coletivos, quando os assistentes sociais estiveram inseridos nas lutas sociais mais amplas da sociedade brasileira e, em particular, na construção de um projeto ético político-profissional, balizado pela maturação no conjunto da classe trabalhadora. Porém, para que princípios e valores se expressem na ética cotidiana é preciso tê-los em constante movimento.

Finalizando esta reflexão que é um chamado para que a categoria não titubeie na defesa de direitos humanos, reafirmando que é um princípio ético fundamental o exercício profissional comprometido com uma nova ordem societária, lembro das palavras de Regina Marconi Franco, em 2009, contido na publicação do Seminário Nacional "30 anos do Congresso da Virada":

Era necessário construir novos rumos para o país e cada um de nós tinha a responsabilidade por parcelas dessa construção. A cada um, a cada segmento, era dada a tarefa de se tornar parceiro para pôr fim no longo período da ditadura e iniciar, de forma plena, o período de redemocratização no Brasil. Tínhamos nas mãos a tarefa compartilhada de toda uma geração, tínhamos um compromisso com o futuro. $\mathrm{O}$ trabalho que se seguiu foi coletivo, nacional. Tornamo-nos companheiros na desconstrução e na construção de conceitos, práticas, currículo mínimo, currículos plenos, o nosso Código de Ética, das normas institucionais, de nossas inserções nos sindicatos, do nosso entendimento do papel dos Conselhos Federal e Regionais, dos destinos deste nosso país. Criamos laços, tivemos divergências. [...] O projeto ético-político em curso no Serviço Social é fruto desse processo vigoroso. Espero que ele se mantenha como sucessor do sonho que até hoje nos impulsiona e inspira (FRANCO, 2009, p.130).

É preciso fazer balanços, avaliar criticamente o que acumulamos e no que nos fragilizamos, com vistas a seguir na construção deste projeto plural e democratizante Serv. Soc. \& Saúde, Campinas, SP v.15, n. 1 (21), p. 83-100, jan./jun. 2016 ISSN 1676-6806 
fundado no acúmulo das lutas dos trabalhadores na construção de uma sociedade sem opressão de classe, etnia e gênero. A questão da democracia, ou democratização como preferimos, se coloca com maior força nestes últimos anos no mundo e no Brasil por razões históricas: a cena contemporânea exige radicalizarmos nossa concepção e lutas democráticas e democratizantes.

Recebido em 29.03.2016 - Aprovado em 27.06.2016

\section{REFERÊNCIAS}

CFESS. 30 anos do Congresso da Virada. Brasília: 2009.

CFESS. III CBAS: algumas referências para sua contextualização. In: CFESS. 30 anos do Congresso da Virada. Brasília, 2009. p. 15-42. Disponível em:

http://www.cfess.org.br/arquivos/SEM30ANOSDAVIRADACFESSsite.pdf

CFESS. Código de Ética Profissional. Acesso em 01/02/2016, www.cfess.org.br DEL ROYO, M. Lukács e a democratização socialista. In: DEL ROYO, M. (Org.) György Lukács e a emancipação humana. São Paulo: Boitempo Editorial; FAPESP; Oficina Universitária. 2013.

FRANCO, R. M. Processo e significado da Virada. In: CFESS. 30 anos do Congresso da Virada. Brasília, 2009, p.121-130.

LUKÁCS, G. Capitalismo Monopolista e Serviço Social. $3^{\text {a }}$ edição ampliada. São Paulo: Cortez, 2001.

LUKÁCS, G. Socialismo e Democratização. Escritos políticos 1956 -1971. Rio de Janeiro: Editora UFRJ, 2011.

NETTO, J. P. Transformações societárias e Serviço Social - notas para uma análise prospectiva da profissão no Brasil. Serviço Social \& Sociedade. São Paulo, Cortez, ${ }^{0}$ 50, ano XVII, abril de 1996, p. 87-132.

WOOD, E. M. Democracia contra o capitalismo: a renovação do materialismo histórico. $1^{\mathrm{a}}$ reimpressão. São Paulo: Boitempo, 2006. 


\section{SITES}

Para DIAP, Congresso eleito é o mais conservador desde 1964.

Disponível em <http://justificando.com/2014/10/10/para-diap-congresso-eleito-e-o-maisconservador-desde-1964/> . Acesso em 25/02/2016. 
